\title{
A EDUCAÇÃO AMBIENTAL E AS PRÁTICAS PEDAGÓGICAS NO ENSINO DE JOVENS E ADULTOS EM FORMOSA - GOIÁS
}

\author{
Marcos Vinicius Santos Dourado ${ }^{1}$
}

Resumo: A educação ambiental é uma prática importante para a educação formal no contexto brasileiro. Tal afirmação a coloca como um elemento pedagógico que precisa ser acompanhado de forma dinâmica para verificar o seu bom andamento no contexto educacional brasileiro. No entanto, essa análise na modalidade do Ensino de Jovens e Adultos ainda é pouco investigada. Através disso, essa pesquisa teve por objetivo analisar como os professores da Educação de Jovens e Adultos das unidades escolares municipais de Formosa (GO) desenvolvem práticas pedagógicas de educação ambiental através da verificação no Projeto Político Pedagógico (PPP) das escolas e a conferência das percepções dos alunos e professores sobre a Educação ambiental e sua prática bem como identificar quais são as práticas mais utilizadas nas escolas. A metodologia foi baseada no método misto, descritivo, modalidade levantamento de dados, aos quais apresentaram práticas baseadas em projetos nos PPPs analisados, com pouca abordagem conceitual. As percepções dos professores se mostraram condizentes com os conceitos de EA e meio ambiente, porém há pouca participação na execução das práticas pedagógicas determinadas no PPP. Já os alunos valorizam as práticas executadas pela escola, porém acham pouco o espaço dos projetos e reclamam de mais participação e engajamento da comunidade. As práticas de EA das escolas analisadas são pautadas basicamente por projetos, com pouca participação dos professores, se restringindo o trabalho das questões ambientais em sala de aula através de debates, aulas expositivas com utilização de recursos variáveis como livro didático, $\mathrm{TV}$, filmes e documentários.

Palavras-chave: Educação. Meio Ambiente. Ensino

\section{ENVIRONMENTAL EDUCATION AND PEDAGOGICAL PRACTICES IN TEACHING YOUTH AND ADULTS IN FORMOSA - GOIÁS}

\begin{abstract}
Environmental education is an important practice for formal education in the Brazilian context. Such an affirmation places it as a pedagogical element that needs to be accompanied dynamically to verify its good progress in the Brazilian educational context. Nevertheless, this analysis in the modality of the Education of Youths and Adults is still little investigated. Through this, this research aims to analyze how the teachers of the Education of Young and Adults of the municipal school units of Formosa (GO) develop pedagogical practices of environmental education through verification in the Political Pedagogical Project (PPP) of the schools and the conference of the perceptions of students and teachers about environmental education and its practice as well as identify which practices are most used in schools. The methodology was based on the mixed method, descriptive, data collection modality, which presented project - based practices in the PPPs analyzed, with little conceptual approach. The teachers' perceptions were consistent with the concepts of EE and environment, but there is little participation in the implementation of pedagogical practices determined in the PPP. The students value the practices carried out by the school, but they find little space in the projects and demand more participation and community engagement. The EE practices of the
\end{abstract}

\footnotetext{
${ }^{1}$ Mestre em Ciências da Educação. Especialista em Estudos dos Solos (Análise Física, Pedologia e Recuperação Ambiental) e Solos e Meio Ambiente. Graduado em Geografia. Professor de Geografia da Secretaria de Estado da Educação, Cultura e Esporte de Goiás (SEDUCE/GO) e Secretaria Municipal de Educação de Formosa (GO). E-mail: mvsd82@gmail.com
} 


\section{REVISTA ELETRÔNICA \\ DA GRADUAÇÃO/PÓS-GRADUAÇÃO EM EDUCAÇÃO \\ UFG/REJ}

analyzed schools are basically based on projects, with little participation of teachers, restricting the work of environmental issues in the classroom through debates, lectures using variable resources such as textbooks, TV, films and documentaries.

Keywords: Education. Environment. Teaching.

\section{INTRODUÇÃO}

A (EA) educação ambiental é uma ação permanente e importante dentro do contexto da educação formal do sistema basilar de ensino brasileiro. Tal afirmação coloca as práticas ambientais como uma atividade de cunho sócio ambiental que busca na formação das crianças, jovens, adultos e idosos desenvolver atitudes que leve o aluno ao desenvolvimento do pensamento crítico, através de reflexões e ações diante das questões ambientais de nossa sociedade contemporânea, tais como: consumismo, o uso indiscriminado dos recursos naturais, o aquecimento global, o desemprego, a miséria, fome entre outros males. Sabendo de sua relevância cabe sempre avaliar o andamento das práticas. Contudo, no que tange a Educação de Jovens e Adultos essa observação carece de uma reflexão sobre seu panorama.

Como problema inicial desta pesquisa se tem a seguinte questão: Como os professores desenvolvem práticas de Educação Ambiental no Ensino de Jovens e Adultos em unidades escolares municipais de Formosa (GO)?

A partir da problemática foi estabelecido o objetivo geral da pesquisa que se permite analisar como os professores da Educação de Jovens e Adultos das unidades escolares municipais de Formosa (GO) desenvolvem práticas pedagógicas de educação ambiental.

Para se chegar a esse objetivo, foram pontuados três objetivos específicos para esta pesquisa: Primeiramente, buscou-se verificar no Projeto Político Pedagógico (PPP) das escolas as abordagens sobre educação ambiental na modalidade EJA - Educação de Jovens e Adultos.

Como segundo objetivo específico foi destacado como ação, conferir a percepção de professores e alunos da (EJA) sobre a educação ambiental e sua prática nas escolas municipais. 


\section{REVISTA ELETRÔNICA \\ DA GRADUAÇÃO/PÓS-GRADUAÇÃO EM EDUCAÇÃO UFG/REJ}

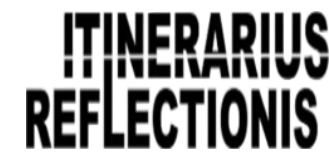

ISSN. 1807-9342

Volume 14, N. 2, 2018

E por último, o terceiro objetivo específico: Identificar as práticas pedagógicas de educação ambiental das escolas municipais no Ensino de Jovens e Adultos em Formosa (GO).

A questão ambiental é de grande relevância no contexto atual, diante de todos os problemas que estamos vivenciando, como o aquecimento global, desastres ambientais, consumismo, individualismo, violência, entre tantos outros problemas socioambientais.

Em âmbito social, o debate sobre a questão ambiental dentro de uma perspectiva da educação ambiental ainda carece de mais vontade do Estado para seu funcionamento pleno. Nas últimas décadas, muito tem sido feito em âmbito da educação básica no sistema regular, porém na Educação de Jovens e Adultos (EJA) existe uma carência em abordagens sobre a Educação Ambiental. Na perspectiva científica se justifica pela importância do desenvolvimento da temática ambiental nas unidades de escolarização básica, pois, tendo em vista o objetivo da educação de formar cidadãos plenos e capazes de exercer sua crítica e ação na sociedade, nada mais importante que desenvolver pesquisas que verificam o desenvolvimento da educação ambiental nas salas de aulas para procurar sempre estar atualizada, contemporânea, eficaz e condizente com o perfil atual dos alunos.

\section{EDUCAÇÃO AMBIENTAL}

O conceito de EA sofreu diversas transformações, em especialmente decorrente do contexto histórico e acadêmico. Conforme as visões sobre Meio Ambiente mudam, esse conceito também se renova. Existem inúmeras visões e conceitos sobre ambos, no início os conceitos eram bastantes restritos, reduzidos basicamente aos aspectos naturais, com o decorrer do tempo e a complexidade e aprofundamento das discussões essa dinâmica foi se alterando.

De acordo Stapp (1969) citado por Dias (2004), “A EA era definida como um processo que deveria objetivar a formação cidadã, cujos conhecimentos acerca do ambiente biofísico e seus problemas associados pudessem alertá-los e habilitá-los a resolver seus problemas" (p. 98). Trazendo de forma evidente uma abordagem bastante restritiva do campo de ação da EA, mantendo um caráter descritivo dos fenômenos naturais, colocando-os como suficiente para resolver as problemáticas existentes. 


\section{REVISTA ELETRÔNICA \\ DA GRADUAÇÃO/PÓS-GRADUAÇÃO EM EDUCAÇÃO UFG/REJ}

\section{ITINEPRARIIUS REFLECTONIS}

ISSN. 1807-9342

Volume 14, N. 2, 2018

Com Mellows (1972) citado por Dias (2004), a EA avança de forma positiva ao desenvolvimento do que podemos chamar de senso de preocupação, uma sensibilização as questões do homem e o Meio Ambiente. Note que há uma separação do homem e ambiente. Cronologicamente foi neste período em que as discussões sobre a quebra desta separação começavam a entrar em vigor.

No documento mais importante no que se refere a EA, Conferência de Tbilisi (1977), “a EA é entendida numa perspectiva de formação e informação, através da resolução de questões relacionadas ao próprio meio, através de uma abordagem interdisciplinar, com uma participação ativa e consciente de cada indivíduo e da sociedade" (p. 99). Essa definição traz um impacto e um entendimento mais profundo da atividade em si. Fazendo com que esta rompa o campo apenas discricional e a torne responsabilidade do coletivo social do mundo contemporâneo.

Ainda destacando Dias (2004), em um dado ponto de sua obra que ele enfatiza novamente Meadows, ele destaca uma sequência de definições do que seria EA:

É o aprender a gerir e melhorar as relações sociedade e ambiente; Preparação para a vida na biosfera; aprender novas técnicas e evitar gastos e danos; valorizar e saber lidar com os sistemas ambientais; aprender a valorizar as diferentes perspectivas do cenário mundial entendendo a diversidade como importante fator para ações que possam resolver as questões ambientais de nossa sociedade (p. 99).

Esses apontamentos de Meadows trazem um leque de ações relevantes, dentre os quais se pode destacar a valorização da diversidade como forma de aprendizagem em relação a EA, ações que até então não haviam sido mencionadas nas definições.

Loureiro (2012), aponta que a Educação Ambiental definida no Brasil é velada a partir de uma matriz que vê a educação como elemento de transformação social inspirada no diálogo, no exercício da cidadania, no fortalecimento dos sujeitos, na superação das formas de dominação capitalistas e na compreensão do mundo em sua complexidade e da vida em sua totalidade. Nesta definição foi elevado a um nível superior as discussões tanto em profundidade como em ampliação dos horizontes dos debates, como destacado nos termos complexidade e diálogo que terá uma discussão mais profunda em na seção 1.2 que abordarão os conceitos sobre meio ambiente.

Uma definição mais politizada e de cunho crítico é a de Marcos Reigota (2014), segundo o mesmo, a Educação Ambiental (EA): 


\section{REVISTA ELETRÔNICA \\ DA GRADUAÇÃO/PÓS-GRADUAÇÃO EM EDUCAÇÃO \\ UFG/REJ}

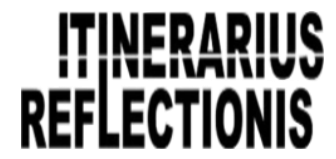

ISSN. 1807-9342

Volume 14, N. 2, 2018

É em um primeiro momento uma prática de sensibilização que estimula o homem à um pensamento crítico sobre as questões ambientais que regem a sociedade em todos os seus âmbitos e setores, social, econômico, político, ecológico numa perspectiva de sustentabilidade (p. 11).

É dever da EA trabalhar o pensamento crítico de forma que a sociedade o tenha como princípio básico.

Todas essas definições compõe o processo de construção histórica que a EA foi submetida sendo aos poucos preenchidas as lacunas, seguindo este processo e nesta perspectiva vamos verificar a História da Educação Ambiental no cenário global.

\section{PRÁTICAS PEDAGÓGICAS EM EDUCAÇÃO AMBIENTAL}

Segundo o PNEA abordado por Dias (2004) a educação ambiental é presente em duas formas básicas: a educação ambiental informal, ou seja, diferente daquilo presente nas instituições formais de ensino de um Estado. Essa educação é presente no dia-a-dia e no cotidiano da sociedade civil, sendo executada por cidadãos nos mais variados setores: Organizações não governamentais (ONG’s), Empresas públicas e privadas, Sociedades anônimas, Associações de moradores, Comunidades, todas com o objetivo de trazer à tona as questões ambientais e fazer com que os cidadãos possam debater e se fazer ativo nas discussões perante sua realidade, levando o lema agindo o local e influenciando o global.

Muito tem se discutido no território brasileiro sobre os rumos da Educação Ambiental, de acordo Reigota (2004), a educação ambiental tem o caráter interdisciplinar e transversal, ou seja, deve ser discutida e estar presente em toda a educação básica adentro as competências e habilidades das mais variadas disciplinas. Esta prática ambiental não pode ser trabalhada como uma disciplina isolada, haja visto que as questões ambientais estão presentes em todos os setores da sociedade e logo, como a escola retrata a sociedade, não pode ser talhada e trabalhada como se não houvesse conexão com o mundo real, como crítica corroborada por Reigota, podendo obter o risco de a educação ambiental se tornar uma Educação Moral e Cívica há anos esquecida nos distantes anos 1980 da educação brasileira. 


\section{PRÁTICAS PEDAgógiCAS EM EDUCAÇÃO AMBIENTAL E ENSINO DE JOVENS E ADULTOS: discussões em âmbito científico}

Com o avanço da discussão acerca da Educação Ambiental em suas inúmeras perspectivas, o mundo cientifico tem avançado nas pesquisas deste setor da educação. Na pesquisa realizada por García (2001), intitulada: Educación ambiental para personas mayores, este estudo aborda a criação de um programa de Educação Ambiental voltada para adultos e idosos em três âmbitos: Rural, Urbano e semi-industrial. Esta pesquisa descreve e analisa a experiência através de método qualitativo, etnográfico, apresentando novos caminhos e propostas para a Educação Ambiental para adultos. A autora conclui que é necessário um olhar diferenciado, condizente e contextualizado diante do processo de ensinar e aprender com jovens, adultos e idosos, pois estes sujeitos possui características próprias que são importantes no desenvolver pedagógico.

Em investigação científica, Paranhos \& Shuvartz (2013), refletem a respeito da formação continuada dos professores bem como uma reformulação da proposta pedagógica do município de Goiânia em relação a Educação de Jovens e Adultos, para que se possa contemplar de forma mais ampla a educação ambiental.

Outro trabalho abordado tem como enfoque a conscientização ambiental fazendo uma trajetória da educação formal a não formal, onde Reis, Sêmedo e Gomes (2012), abordam que a educação ambiental é um processo em permanente construção e tem como objetivo promover a renovação da percepção individual sobre as questões ambientais utilizando um senso crítico, de forma local e global, possibilitando não só o acesso a novos conhecimentos, mas também despertando valores e tomando novas atitudes perante o meio que vive.

É relevante destacar este ponto, quebrando aquele paradigma, já atrasado, porém ainda executado do reducionismo da educação ambiental de apenas adquirir conhecimento ecológico e de funcionamento dos sistemas. É importante o conhecimento dos sistemas físico-naturais, tem sempre de ser abordado, porém a forma como é percebido e as atitudes e os valores adquiridos pelos indivíduos e como serão suas ações a partir daquelas visões é de fundamental importância.

Trolezi (2016), conclui em seu trabalho sobre a Educação Ambiental e a aprendizagem de alunos de EJA que é evidente a falta de contato dos alunos com as 


\section{REVISTA ELETRÔNICA \\ DA GRADUAÇÃO/PÓS-GRADUAÇÃO EM EDUCAÇÃO \\ UFG/REJ}

questões ambientais. Muitos tiveram pouco acesso apenas quando estudavam no ensino regular, e que o contato na EJA só se dá mediante a poucas aulas expositivas ou acesso a textos curtos sobre as questões ambientais.

No Estudo de Farias \& Claro (2016) que aborda a educação ambiental na educação de jovens e adultos e a construção do diálogo, foi destacado a ausência das questões ambientais nas aulas dos professores e que muitos alunos associam a educação ambiental apenas ao viés ecológico, tendo a necessidade de um trabalho mais amplo e transversal na prática da Educação Ambiental.

Sendo assim, por meio dessas diversas pesquisas, fica exposto os diversos problemas e percalços em relação ao currículo da Educação de Jovens e Adultos. Devese lembrar que existem muitos Estados apenas uma condensação do currículo da educação regular, não favorecendo as necessidades e peculiaridades do aluno de EJA, o que acarreta em um prejuízo no processo de ensino, e afeta consequentemente a educação ambiental que deveria ser efetivada.

Outro aspecto de relevância a ser notado, é a questão da formação continuada, haja visto que a Educação Ambiental é dinâmica, está sempre em processo de mudança e o professor tem que se manter atualizado, neste ponto é fundamental a presença do Estado no fornecimento desta formação continuada aos seus educadores.

\section{ASPECTOS METODOLÓGICOS}

De acordo Vieira (2001):

Formosa está localizada na região leste de Goiás, (Figura 01) à 280 km da capital, Goiânia, e a $75 \mathrm{~km}$ da capital federal, Brasília. A região central da cidade está somente a $5 \mathrm{~km}$ da divisa com o Distrito Federal. Na porção Norte do município limita-se os municípios de São João D’Aliança, Vila Boa e Flores de Goiás. Ao sul com Unaí (MG) e também como o Distrito Federal. Na direção leste limita-se com Cabeceiras de Goiás, Buritis (MG) e Formoso (MG) e na direção leste com São João D’Aliança, Planaltina de Goiás e Distrito Federal (p.61). 


\section{REVISTA ELETRÔNICA \\ DA GRADUAÇÃO/PÓS-GRADUAÇÃO EM EDUCAÇÃO \\ UFG/REJ}

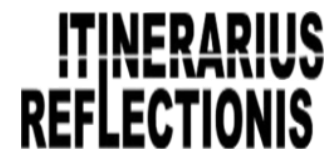

ISSN. 1807-9342

Volume 14, N. 2, 2018

Figura 01: Localização do município de Formosa - Goiás

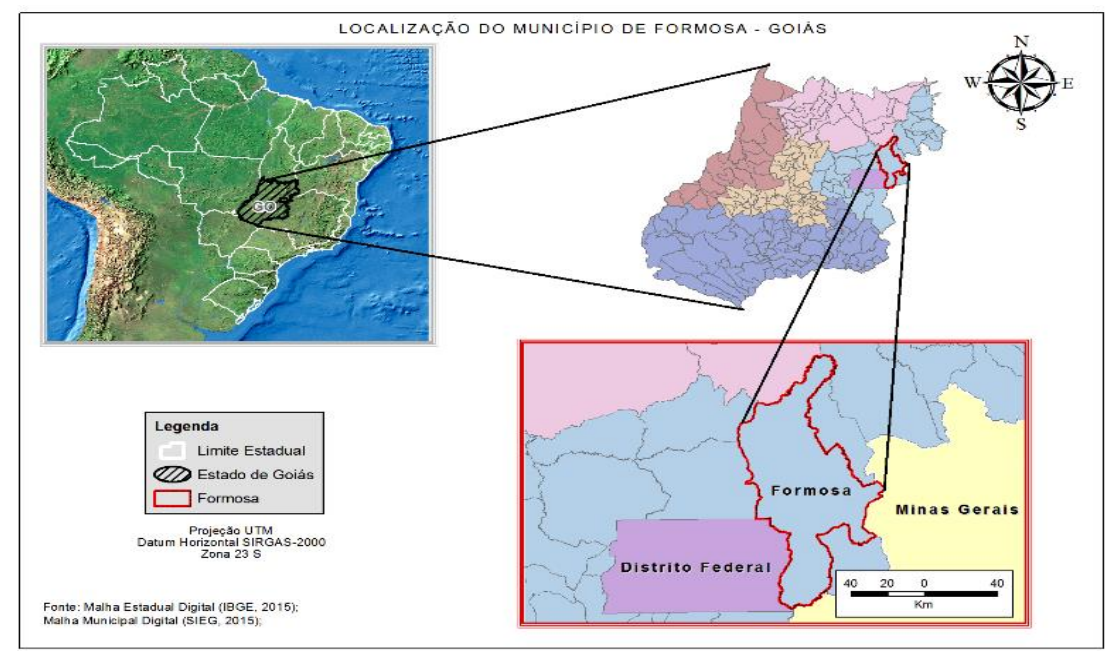

Elaborado por: Oliveira, E. (2017).

A pesquisa foi realizada nas Escolas Municipais de Formosa que possuem a modalidade de Ensino de Jovens e Adultos (EJA) de $2^{\circ}$ segmento. Sendo as unidades de ensino, neste trabalho, chamadas de Escola (A); Escola (B) e Escola (C) (Figura 02), com vistas a preservação da identidade de cada instituição participante, localizadas nos setores: Nordeste, Formosinha e Bosque I.

Figura 02: Localização das escolas municipais pesquisadas.

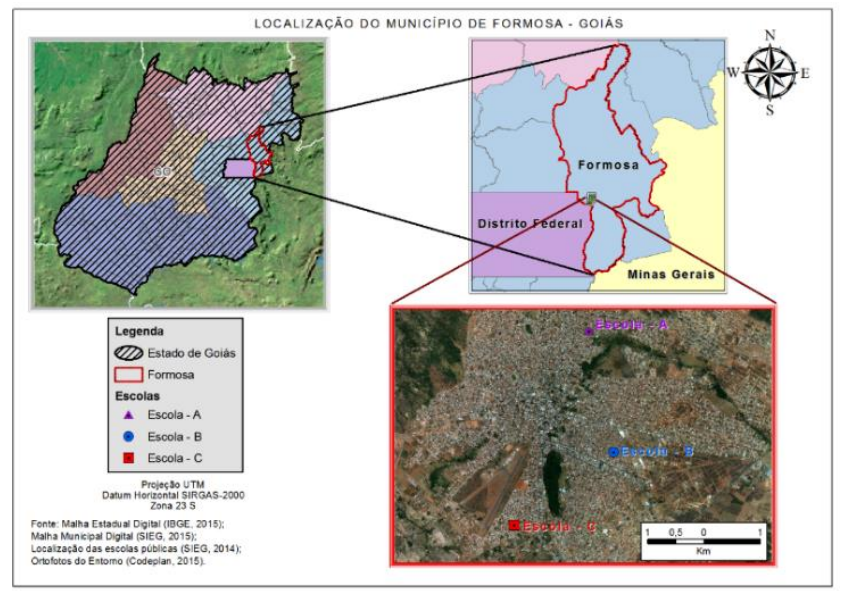

Elaborado por: Oliveira, E. (2017). 


\section{REVISTA ELETRÔNICA \\ DA GRADUAÇÃO/PÓS-GRADUAÇÃO EM EDUCAÇÃO \\ UFG/REJ}

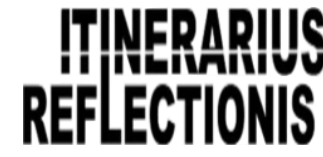

ISSN. 1807-9342

Volume 14, N. 2, 2018

O modelo desta pesquisa será não experimental, se trata de uma pesquisa mista. As definições mais significativas do enfoque misto ou os métodos mistos são as seguintes segundo Sampieri et al. (2013)

I. Os métodos mistos apresentam um conjunto de processos de investigação sistemática, empírica e crítica onde envolve análise de dados quantitativos e qualitativos, e a sua integração ou discussão conjunta, para fazer inferências do produto de todas as informações coletadas e uma maior compreensão do fenômeno em estudo;

II. Os métodos de investigação mista são a investigação sistemática de métodos quantitativos e qualitativos em um único estudo a fim de obter um fenômeno "fotografia" mais completo. Estes podem ser unidos para que as abordagens quantitativas e qualitativas mantêm a suas estruturas e procedimentos originais (forma modificada de métodos misto).

Campoy (2016) destaca que o estudo de métodos mistos "utilizam distintos métodos, por exemplo, utilizar a técnica de entrevista e questionários fechado de respostas simples" (p. 452).

A pesquisa será do tipo descritivo, modalidade levantamento de dados, onde, segundo Babbie (2011) é um tipo de abordagem que visa apresentar opiniões das pessoas por meio de questionários ou entrevistas. Segundo Apollinário (2015), a pesquisa de levantamento "tem por finalidade investigar as características de determinada realidade ou descobrir as variáveis componentes dessa realidade" (p.119).

$\mathrm{O}$ foco da pesquisa foi a educação ambiental no ensino de jovens e adultos e o objeto de investigação foram as práticas de EA realizadas por professores e alunos que, a partir do estudo prévio, foi possível delimitar alguns indicadores do processo.

A População está delimitada dentro do universo das três Escolas Municipais, sendo os sujeitos da pesquisa os docentes e alunos da Educação de Jovens e Adultos, com um total de 231 alunos e 12 professores. Para facilitar a coleta de dados será feita amostragem do quantitativo de alunos, com uma margem de erro de $5 \%$ e nível de confiança de $95 \%$, tendo a amostra de 144 alunos.

$$
\begin{aligned}
& n=\frac{N \cdot \mathrm{p} \cdot \mathrm{q} \cdot z^{2}}{p \cdot q \cdot z^{2}+(N-1) \cdot \mathrm{e}^{2}} \\
& n=\frac{231 \times 0,9604}{0,9604+(230 \times 0,0025)}=144 \text { alunos. }
\end{aligned}
$$




\section{REVISTA ELETRÔNICA \\ DA GRADUAÇÃO/PÓS-GRADUAÇÃO EM EDUCAÇÃO \\ UFG/REJ}

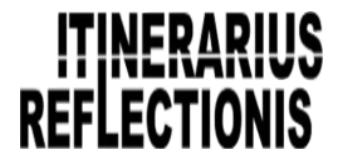

ISSN. 1807-9342

Volume 14, N. 2, 2018

Em relação aos professores serão pesquisados a população total, ou seja, os 12 professores. Serão utilizados alguns critérios para a seleção dos alunos, serão excluídos da pesquisa os alunos não frequentes, ou recém matriculados no ato da aplicação dos instrumentos de coleta de dados. Estes dados se equivale ao $2^{\circ}$ semestre 2017.

Em suma, as técnicas utilizadas foram: questionários semiabertos, guia de entrevista e análise de documentos. Os questionários para conferir junto aos alunos a percepção destes sobre as práticas de educação ambiental na (EJA) das escolas municipais analisadas. Igualmente serão realizadas entrevistas junto aos professores afim de identificar as práticas de educação ambiental realizadas na Escola estudada, bem como a percepção dos mesmos sobre essas atividades. A análise de documentos partirá do Projeto Político Pedagógico (PPP) das escolas, verificando as práticas de EA existentes nas unidades escolares.

De acordo com os aspectos éticos, foi solicitado formalmente que a coleta de dados seja realizada nas escolas pesquisadas, com pedido de autorização encaminhado a Secretaria Municipal de Educação de Formosa (GO), bem como as unidades escolares e seus gestores. Será enviado, posteriormente, o Termo de Consentimento Livre e Esclarecido - TCLE, a fim de atingir os procedimentos exigidos, determinados pela Resolução 196/96 do Conselho Nacional de Saúde. O projeto de pesquisa foi submetido a análise do Conselho de Ética de Pesquisa com seres humanos através da Plataforma Brasil, sendo aprovado conforme Parecer No 2.238.684, CAAE 69439517.5.0000.0023.

\section{RESULTADOS OBTIDOS}

Dentro dos objetivos específicos alinhados para esta pesquisa, primeiramente foi realizada a verificação das práticas de EA existentes no PPP das escolas, em segundo lugar a percepção dos professores e logo em seguida a percepção dos alunos diante das práticas de EA presentes na EJA.

\section{VERIFICAÇÕES DAS PRÁTICAS DE EA EXISTENTES NOS PPP DAS ESCOLAS}

A análise dos PPP's das três escolas foram feitas durante o mês de agosto de 2017. Os documentos foram analisados in loco, com auxílio da lista para análise dos 


\section{REVISTA ELETRÔNICA \\ DA GRADUAÇÃO/PÓS-GRADUAÇÃO EM EDUCAÇÃO UFG/REJ}

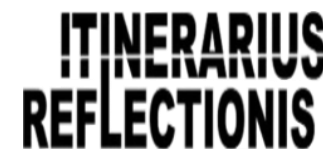

ISSN. 1807-9342

Volume 14, N. 2, 2018

documentos. Segue a descrição dos resultados obtidos nas análises de cada Projeto Político Pedagógico.

Em relação a Escola (A), o PPP não evidencia nem descreve no capítulo relacionado ao corpo docente a especialização nem a descrição do curso. O que dificulta a verificação desse indicador no documento analisado. No PPP da Escola (A) foi percebido como pontos importantes: Valorizam a união e cooperação com a comunidade escolar, a todo momento é invocado o tema no PPP; valorização a formação cidadã e o desenvolvimento do pensamento crítico do aluno; A abordagem do tema interdisciplinaridade inclusive no perfil do professor; valorizam a formação continuada, está evidenciada no decorrer do texto. Esses indicadores analisados no PPP da Escola, trazem informações que ilustram o quadro geral apresentado enquanto articulação de ações de cunho pedagógico na unidade escolar.

Como objetivo da Escola B, (2017) em seu PPP tem na base "o ideal coletivo se compromete com uma prática libertadora, visando desenvolver ações de intervenção na realidade para que estas possam aumentar a eficiência escolar, preparando o aluno para vivenciar um universo de constantes mudanças, observando valores éticos, políticos, estéticos e religiosos" (p.05), é interessante pois a escola preocupa-se com a formação do indivíduo como cidadão presente e atuante na sociedade.

Em relação aos projetos das 20 propostas listadas no PPP, quatro abrangem algumas características de educação ambiental, descritas nas propostas e embasadas nos temas transversais como Ética, Cidadania e Meio Ambiente.

Segundo o PPP da Escola B (2017), “a formação continuada é incentivada através da progressão funcional baseada na titulação ou habilitação e na avaliação do desempenho", (p. 43). Seguindo assim as prerrogativas da Lei de diretrizes e bases da educação.

O PPP não evidencia nem descreve no capítulo relacionado ao corpo docente a especialização nem a descrição do curso. O que dificulta a verificação desse indicador no documento analisado.

A Escola C (2017) e seu projeto político pedagógico no que tange os objetivos em relação a formação do aluno, em sua introdução a escola aborda que "busca proporcionar a formação de alunos competentes em relação ao trabalho que realizam e estimular o compromisso com a transformação social, tratando de forma consciente e 


\section{REVISTA ELETRÔNICA \\ DA GRADUAÇÃO/PÓS-GRADUAÇÃO EM EDUCAÇÃO UFG/REJ}

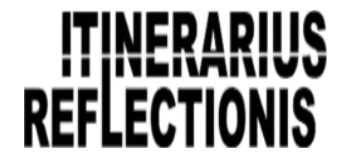

ISSN. 1807-9342

Volume 14, N. 2, 2018

intencional de fazer política fazendo educação". São destacados como pontos importantes da Escola (C): Valorizam a formação do aluno e o desenvolvimento do pensamento crítico, a todo momento é citado no PPP; busca também uma formação cidadã baseada em princípios e valores, muito citada no texto e a existência de vários projetos com a presença da educação ambiental, tanto no desenvolvimento das práticas como nos temas transversais.

Agora, cabe analisar a percepção dos professores em relação as práticas pedagógicas de Educação Ambiental.

\section{A PERCEPÇÃO DOS PROFESSORES DAS ESCOLAS}

Em suma, no que tange a Escola (A), as percepções apresentadas pelos professores apresentam-se bem sinceras e objetivas, porém, é destacado um pouco engajamento nas ações que tange as práticas pedagógicas em EA na EJA. O que contradiz o estabelecido no PPP, onde existem projetos a serem desenvolvidos aos quais alguns professores dizem não participar de qualquer atividade nem projetos. Falta formação específica na área, o que traz mais problemas para as práticas pedagógicas de EA.

Resumindo sobre a Escola (B), a percepção dos professores é um tanto contraditória, principalmente na relação projetos, planejamento das aulas e o PPP da escola. Há uma série de equívocos nas respostas, pois muitos dizem "Não participar de projetos dentro ou fora do ambiente e escolar", no entanto afirmam trabalhar com projetos em seu planejamento. O PPP da escola apresenta algumas ações que não estão sendo executadas, ou, sendo articuladas por poucos professores, no caso, apenas um professor diz participar dos projetos.

Sobre a Escola (C), novamente, uma escola que apresenta problemas e contradições na articulação PPP e suas ações na prática em sala de aula. Os professores não participam dos projetos articulados pela escola, isso é um problema, pois apresenta desorganização e falta de coerência na articulação das práticas pedagógicas. Outro ponto a ser destacado é a falta de formação na área, o que também elucida as dificuldades na articulação das propostas previamente estabelecidas na construção dos PPP's das escolas analisadas. 


\section{REVISTA ELETRÔNICA \\ DA GRADUAÇÃO/PÓS-GRADUAÇÃO EM EDUCAÇÃO \\ UFG/REJ}

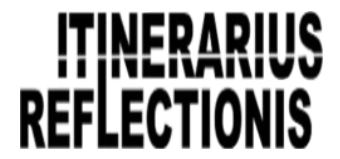

ISSN. 1807-9342

Volume 14, N. 2, 2018

Para fechar a análise das percepções partimos para o outro lado: a percepção dos alunos sobre as práticas de Educação Ambiental no âmbito da EJA.

\section{A PERCEPÇÃO dOS ALUNOS SOBRE AS PRÁTICAS DE EDUCAÇÃo AMBIENTAL}

Observa-se em síntese na Escola (A) que os alunos valorizam as práticas pedagógicas de EA na escola, acham importante, principalmente os projetos e as aulas dos professores, porém apontam que a falta de mais projetos e a pouca participação da comunidade são pontos negativos para essas práticas. Há um entendimento do conceito de Meio Ambiente que de certa forma também atrapalha o desenvolvimento das práticas, pois muitos deles entendem como "natureza isolada".

Os alunos pesquisados na Escola (B), elencaram como pontos negativos a "falta de projetos" em primeiro lugar, seguido da "pouca participação da comunidade" e em terceiro lugar as aulas dos professores. Podemos aferir dos dados a relação com a valorização dos projetos, já que a maioria enfatiza a falta de projetos. Relacionando com o gráfico anterior depreende-se que existem projetos, os alunos gostam, porém, são poucos projetos. O que vai de encontro com o analisado no PPP da escola analisada que apresentam uma série de projetos relacionados a temática ambiental.

Fechando a análise da percepção dos alunos em relação as práticas pedagógicas de Educação Ambiental na Escola (B); onde ficou claro que os alunos valorizam a presença da Educação Ambiental, acham muito importante. Gostam das aulas dos professores, dos projetos executados, porém acham que deveriam ter mais projetos na escola.

Após a análise da percepção dos alunos da Escola (C) foi percebido um cenário semelhante as outras duas escolas analisadas: Os alunos valorizam as aulas dos professores, gostam dos projetos executados por elas, acham bons projetos, porém apontam a falta de mais projetos e também a falta de participação da comunidade para a boa execução dos projetos. Acham bastante importante a presença da EA nas Escolas e valorizam a execução dessas práticas enquanto ações transformadoras do indivíduo enquanto cidadão.

Em síntese, observa-se analisando e comparando os dados das três escolas que, primeiramente, o perfil dos alunos é bem parecido, em sua maioria formada por jovens 


\title{
REVISTA ELETRÔNICA \\ DA GRADUAÇÃO/PÓS-GRADUAÇÃO EM EDUCAÇÃO UFG/REJ
}

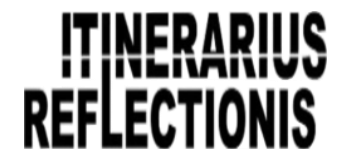

ISSN. 1807-9342

Volume 14, N. 2, 2018

entre 15 e 23 anos, sem profissão estabelecida, ou seja, "estudantes". São dados importantes pois muda o paradigma do perfil do aluno da modalidade de EJA que anteriormente era formado basicamente por adultos maduros e idosos e com profissões além das classes de estudo.

Os alunos apontam a falta de projetos, o que contradiz o estabelecido nos PPPs, porém há uma relação com as entrevistas dos professores onde se observa o pouco engajamento dos professores no desenvolvimento das ações estabelecidas pelo PPP. Porém estes valorizam as aulas dos professores e acham importante a presença da EA nas escolas. Também criticam a falta de participação da comunidade nas escolas.

No entanto, se deve ressaltar que as práticas não podem ser restritas apenas a projetos esporádicos, conforme Reigota (2008):

\begin{abstract}
Como educadores, devemos ter sempre presente que conscientização ambiental é muito mais que campanhas, programas e projetos, geralmente envolvendo temas como "lixo", "água", "poluição", como se fossem demandas isoladas. $O$ que devemos despertar na comunidade escolar é o fato de que a biodiversidade é muito importante, mais importante é que somos uma espécie que compõe esta biodiversidade (p.54).
\end{abstract}

Diante deste cenário avancemos para as considerações finais.

\section{CONSIDERAÇÕES FINAIS}

A EA é uma prática pedagógica que precisa ser costumeiramente verificada sua execução no ambiente escolar, pois se trata de uma prática dinâmica que precisa estar contextualizada e condizente com a sociedade na contemporaneidade. Diante disso, foi realizada essa pesquisa com o intuito de analisar como são feitas as práticas pedagógicas em EA na modalidade de ensino de adultos no âmbito da cidade de Formosa Goiás.

Em primeiro lugar, cabe salientar que esta pesquisa é um avanço sobre os estudos das práticas de Educação Ambiental na modalidade EJA, esta pesquisa percorreu por caminhos pouco explorados para estabelecer as nuances e ampliar os horizontes no que tange a EA e também a Educação de Jovens e Adultos, tão pouco valorizada no espaço acadêmico em nossa conjuntura brasileira de pesquisa em educação. 


\section{REVISTA ELETRÔNICA \\ DA GRADUAÇÃO/PÓS-GRADUAÇÃO EM EDUCAÇÃO UFG/REJ}

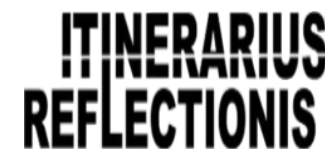

ISSN. 1807-9342

Volume 14, N. 2, 2018

Em relação ao primeiro objetivo específico, verificar no Projeto Político Pedagógico (PPP) das escolas as abordagens sobre educação ambiental na modalidade EJA - Educação de Jovens e Adultos, A pesquisa demonstrou que existem abordagens nos PPPs das três unidades escolares abordadas. Existe um objetivo claro na formação do aluno, alguns PPP’s até bem específicos neste quesito, valorizando a formação cidadã e o desenvolvimento de um pensamento crítico.

A falta de coerência na elaboração de projetos e ações de cunho pedagógico nos PPP's a não participação dos professores na execução destes só configuram um quadro triste de confecção mecânica destes PPP's sem a participação ativa dos professores o que traz uma proposta desvirtuada e desconexa com o que de fato está sendo realizado na prática.

Já o segundo objetivo especifico: Conferir a percepção de professores e alunos da (EJA) sobre a educação ambiental e sua prática nas escolas municipais, a pesquisa teve um resultado positivo. Os professores foram bem claros e sinceros nas respostas o que ajudou no estudo dessas percepções.

$\mathrm{Na}$ análise realizada foi conferido que os professores entendem o que é a Educação Ambiental e o Meio Ambiente e também utilizam os temas e as questões ambientais em sala de aula, muitos realizam projetos e também discutem os temas de forma geral em suas aulas e também valorizam a presença da EA nas escolas, contudo, enfatizam a pouca participação da comunidade como problema para um bom desenvolvimento das práticas pedagógicas em EA.

Os alunos, no entanto, valorizam bastante o que é ensinado nas escolas, gostam dos projetos, aliás, os indicam como pontos fortes das escolas, contudo, acham pouca a quantidade de projetos, pois os mesmos alunos indicaram de forma geral a pouca quantidade destes como debilidades das escolas analisadas.

Outro ponto de atenção levantado é a questão da pouca participação da comunidade. $\mathrm{Na}$ análise dos dados relativos aos alunos e professores foi evidenciado esse ponto. Cabe as escolas no início do ano letivo uma revisão do PPP tendo como prisma uma maior participação da comunidade nos eventos e nas práticas de EA em âmbito escolar. 


\section{REVISTA ELETRÔNICA \\ DA GRADUAÇÃO/PÓS-GRADUAÇÃO EM EDUCAÇÃO UFG/REJ}

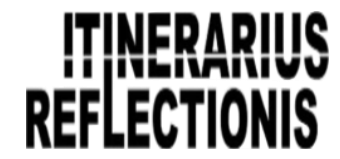

ISSN. 1807-9342

Volume 14, N. 2, 2018

Um fato a se destacar nesta pesquisa foi a diminuição da faixa etária dos alunos de EJA. Estes estão cada vez mais jovens, entre 15 e 23 anos em sua maioria, isso muda o antigo paradigma do aluno de EJA, formado por adultos maduros e idosos.

Este ponto requer das unidades escolares um planejamento voltado para esta característica, já que são alunos com características diferentes deste antigo perfil. Também torna complexa, pois os adultos maduros e idosos ainda estão presentes, porém em menor número, requerendo um planejamento diversificado por parte dos professores.

No que tange o terceiro objetivo específico, identificar as práticas pedagógicas de educação ambiental das escolas municipais no Ensino de Jovens e Adultos em Formosa (GO), essas práticas são baseadas em Projetos específicos realizados durante o ano letivo, embora seja praticada por uma minoria dos professores, há também a presença dos temas relacionados as questões ambientais nas aulas dos professores.

Por fim, os objetivos específicos completam o objetivo geral desta pesquisa que foi analisar como os professores da Educação de Jovens e Adultos das unidades escolares municipais de Formosa (GO) desenvolvem práticas pedagógicas de educação ambiental. Após a realização deste trabalho percebe-se que a EA está presente no cotidiano da EJA, através dos projetos pedagógicos e também nas aulas, contudo, como já relatado aqui anteriormente, necessita de alguns ajustes para assim se tornar atualizada, contextualizada e condizente com a realidade destes alunos.

\section{REFERÊNCIAS}

APPOLINÁRIO, F. Metodologia da ciência: filosofia e prática da pesquisa. $2^{\mathrm{a}}$ ed. São Paulo SP, Cengage Learning, 2015.

BABBIE, EARL. Métodos de pesquisa de survey. 1.ed., Belo Horizonte MG, Edições UFMG, 1999.

CAMPOY, T. J. Metodología de La Investigación Científica, Manual para Elaboración de Tesis Y Trabajos de Investigación. $2^{\text {a }}$ Ed., Ciudad del Este, Paraguay, Editorial: Universidad Nacional del Este, 2016.

DIAS, G. F. Educação Ambiental: Princípios e Práticas. 9a ed., São Paulo, Ed. Gaia, 2004.

ESCOLA A Projeto Político Pedagógico. Formosa (GO), Secretaria Municipal de Educação (SME), 2017. 


\section{REVISTA ELETRÔNICA \\ DA GRADUAÇÃO/PÓS-GRADUAÇÃO EM EDUCAÇÃO \\ UFG/REJ}

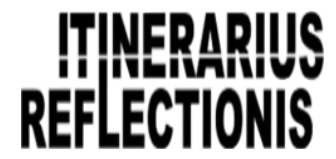

ISSN. 1807-9342

Volume 14, N. 2, 2018

ESCOLA B. Projeto Político Pedagógico. Formosa (GO), Secretaria Municipal de Educação (SME), 2017.

ESCOLA C. Projeto Político Pedagógico. Formosa (GO), Secretaria Municipal de Educação (SME), 2017.

FARIAS, R. M. D., \& CLARO, P. C. G. Educação ambiental na educação de jovens e adultos (eja): um diálogo em construção. Revista Saberes Da UNIJIPA, 2012.

GARCIA, L. B. Educación ambiental para personas mayores. (Tesis de Doctorado en Educación), Universidad Nacional de Educación a Distancia (UNED), Madrid, Espanha, 2001.

LOUREIRO, C. F. B. Trajetórias e fundamentos da educação ambiental. $4^{\mathrm{a}}$ ed. São Paulo SP, Cortez, 2012.

MEADOWS, D.H.; MEADOWS, D.L.; RANDERS, J.; BEHRENS, W.W. Limites do crescimento. São Paulo SP, 1972.

PARANHOS, D. R; SHUVARTZ, M. A relação entre educação ambiental e a educação de jovens e adultos sob a perspectiva da trajetória dos educadores. Revista Contexto e Educação, Ano 28, nº 91, p. 84-105, Ijuí RS, Editora Unijuí, 2013.

REIGOTA, M., Educação ambiental: utopia e práxis. São Paulo SP, Cortez, 2008.

2014. O que é Educação Ambiental. São Paulo SP, Editora Brasiliense,

REIS, L. C. L.; SÊMEDO, L. T. A.; GOMES, R. C., Conscientização ambiental: da educação formal à não formal. Revista Fluminense de Extensão Universitária, Vassouras RJ, V.02, nº1, pág. 47-60, 2012.

SAMPIERI, H. R. et. al. Metodologia da Pesquisa. $5^{\text {a }}$ Ed., Porto Alegre RS, Editora Penso, 2013.

TROLEZI, L. M., Visão Diagnóstica Sobre Aprendizagem da Educação Ambiental na Educação de Jovens e Adultos. Revista Perspectiv@s: Um Novo Olhar sobre a Educação de Jovens e Adultos. № 02, págs. 92 -102, São Paulo SP, Centro Paulo Souza, 2016.

VIEIRA, G. J., Formosa cidade e povo. Brasília DF, Teixeira Gráfica e Editora, 2010. 